\title{
Research on the Public Cognitive Differences of Healthcare Functions of Silk Fabrics for Garment: Based on Research Data from Hangzhou, China
}

\author{
Aijuan Cao ${ }^{1,2}$, Qi Zhu' ${ }^{2}$, Yiling Zhang ${ }^{1} \&$ Lanlan Yan ${ }^{3}$ \\ ${ }^{1}$ Fashion \& Art Design Institute, Donghua University, Shanghai, China \\ ${ }^{2}$ Highfashion Womenswear Institute, Hangzhou Vocational \& Technical College, Hangzhou, China \\ ${ }^{3}$ School of Fashion Engineering, Shanghai University of Engineering Science, Shanghai, China \\ Correspondence: Aijuan Cao, Highfashion Womenswear Institute, Hangzhou Vocational \& Technical College, \\ NO. 68, Xueyuan Street, Xiasha Higher Education District, Hangzhou, 310018, China. Tel: 86-130-6795-9120. \\ E-mail: caoaijuan2005@163.com
}

Received: January 8, 2018

Accepted: January 29, 2018

Online Published: February 26, 2018

doi:10.5539/ass.v14n3p63

URL: https://doi.org/10.5539/ass.v14n3p63

\begin{abstract}
Silk fabrics own a number of excellent qualities, while the public cognition status of on property regarding silk fabrics of the garment is unclear. In this paper, three indicators based on healthcare function as breakthrough point such as anti-mite, anti-bacteria and anti-allergy, healthy and environmentally friendly function, and skin-care function, were used to analyze the status of the public cognition on healthcare function of silk fabrics through questionnaire investigation and statistical analysis based on surveys conducted from the public of Hangzhou, China as core respondents. The result shows that the public owns high cognition on the healthy and environmentally friendly function of silk fabrics of the garment. Factors such as personal preference, purchase and use experience, whether the silk industry practitioners are of a significant impact on healthcare cognition, while gender, age, and years of residence in Hangzhou are of no significant impact.
\end{abstract}

Keywords: silk fabrics, healthcare function, cognition degree, questionnaire investigation

Under the modern social background of pursuing high quality and healthy life, the consumer attitudes advocating green and returning to nature lead people to put forward higher requirements on garment materials. Being difficult to be satisfied with the dressing needs of comfort, beauty, and durability, people pay more attention to the garment function of safety and health, and hygiene. The main component of silk fiber which possesses the excellent characteristics that other fiber cannot compare in healthcare function from the medical point of view is protein, of which the molecular structure is similar to collagen in human skin. Therefore, silk fabrics with its natural and environmentally friendly materials, soft and comfortable wearing experience, and noble and elegant appearance etc. become the first choice of high-grade garment materials.

Functional fabrics refer to fabrics with special functions such as anti-mite and mosquito repellent, waterproof, oil proof and stain proof, fungi proof and anti-microbial, aroma and deodorization, anti-static, radiation proof and flame retardancy besides satisfying the basic use value. According to different needs, special functions of garment fabrics mainly include healthcare function of comfort, hygiene, protection, and others. The paper will study the healthcare cognition degree of silk fabrics of the garment as a breakthrough point in means of questionnaire investigations and field interviews to understand the current public cognition status on the healthcare function of silk fabrics of the garment in daily life, aiming to provide some reference data for the development and marketing of silk garment products.

\section{Research Conception and Method}

Based on the previous studies, the author extracted related quantization indicators to develop a cognitive quantization table for healthcare function of silk fabrics of the garment and then collected standard quantitative data through questionnaire survey by means of subjective evaluation method based on individual perception. At last, possible statistical law and phenomenon worthy of attention or further to be explored from the data through the analysis of survey results by means of SPSS statistical method after collection of questionnaires. 


\subsection{Principle of Healthcare Function of Silk Fabrics}

Deriving from the special physical and chemical structure of silk protein fibers that are porous fibers of which the internal structure is pretty loose and the silk peptide chain contains a large number of hydrophilic groups (-OH, $-\mathrm{COOH},-\mathrm{NH} 2$, etc.) to provide silk fabrics with excellent function of microclimate regulation for garment, silk and silk fabrics possess well-behaved healthcare function, (Xu \& Liang, 1995, pp. 54-57). Therefore, silk fabrics can absorb and remove sweat and discharge from the skin quickly, maintaining the skin dry and clean and inhibiting bacterial production. Containing a large number of useful amino acids, silk fiber possesses functions of defense of ultraviolet radiation, treatment of skin pruritus and others. Silk fiber moisture content is around $11 \%$. Wearing silk fabric next to skin helps to maintain a certain amount of moisture for the skin - not only to maintain skin moisture but also to prevent skin dryness.

With the progress of science and technology, fabrics can be endowed with more special functions through methods of auxiliaries finishing and fiber blending, meanwhile, healthy and environmentally friendly safety features of natural fiber being destroyed to some extent. Therefore, the author will not discuss the healthcare functions of the postnatal treatments. According to relevant information, the author extracts seven common indicators of healthcare effects for human bodies as follows that silk garments mainly possess including defense of ultraviolet radiation, adsorption of harmful gases, treatment of skin pruritus, anti-mite, mildew proof, anti-microbial, anti-allergy to develop the cognitive quantization table for healthcare functions of silk fabrics of garment.

\subsection{Development of the Quantization Table}

\subsubsection{Resistance to UV Radiation}

Sunlight contains a lot of ultraviolet rays, easily leading to skin aging, pigmentation, dark spots and eye disease if with too much exposure. Compared to other fabrics, silk fabrics that prevent and reduce UV-induced skin irritation by reflecting and absorbing ultraviolet rays are with strong function of defense of ultraviolet radiation (Wan \& Hu, 2012, p. 111-113). Studies confirmed that silk fabrics own the lowest ultraviolet transmission (0.0272\% only) among different fabrics of similar thickness (Leng, 1988, p. 34-36; Li, Zhang \& Li, 2007, p.45-47). The tryptophan and the tyrosine in the fiber protein of the silk fiber absorb the ultraviolet rays in the sunlight and generate photochemical reaction with ultraviolet, resulting in the yellowing phenomenon of silk fabrics and thereby protecting the skin from or being less affected by radiation.

\subsubsection{Adsorption of Harmful Gases}

Up to $38 \%$ porosity inside the silk fibers provides the silk fabric a high adsorption capacity to absorb some of the harmful constituents of the air such as ammonia, formaldehyde, $\mathrm{SO} 2$ and carcinogenic substances contained in tobacco smoke (He, 1998, pp. 26-28), reducing the chances of microbes breeding on the skin. under the circumstances of increasingly serious atmospheric pollution, silk garments can effectively block the infringement of harmful gases, providing the human body with a safe, clean environment to ensure that the skin health.

\subsubsection{Treatment of Skin Pruritus}

Silk fibers are truly "natural healthcare fibers" as clinical research have shown that silk garments have a good antipruritic and adjuvant therapeutic effect on various types of skin diseases (Yang, 2001, p. 8). Silk fabric underwear has an effective treatment rate of more than $90 \%$ for a variety of skin Pruritus, comparable to or superior to medical treatment (Yang, 2001, p. 9) and skin diseases can be effectively prevented by wearing silk garments.

\subsubsection{Anti-microbial}

Antibacterial properties of silk garments behave in three aspects: firstly, inhibiting the bacteria bred from human bodies and fabrics; secondly, preventing bacteria outside permeation through the fabrics; and thirdly, killing pathogens; to ensure skin health and health. Xueqian Wang $(1989,1999)$ conducted a comparative test on the antimicrobial properties of various fabrics by the method of the paste and bacteria permeation through the fabrics, and confirmed that the antimicrobial and antibacterial effects of silk fabrics are significant (Wang, Ji \& Xie, 1989, pp. 31-32). Mingying Yang (2001), through the antibacterial test on a variety of fabrics, concluded that "amino acids in silk protein antibacterial inhibits the bacteria on microorganisms". In addition, sun-dried silk garments absorb a certain amount of ultraviolet rays. Therefore, the silk fabrics can absorb sweat discharged from human bodies on one hand and kill pathogens by releasing ultraviolet slowly during wearing (Yang, 2001, p. 14). Moreover, fibrillation of silk also helps to remove the dirt and bacteria attached to the human skins, playing an anti-bacteria effect. 


\subsubsection{Anti-mite, Mildew Proof, Anti-allergy}

With excellent garment microclimate adjustment function, the silk fabrics absorb and discharge sweat quickly when human body sweats, keeping the skin dry and clean to maintain normal physiological state. Wearing next to the skin, garments of silk fabrics can prevent mites and molds from breeding (Yang, 2001, pp. 7-14), to eliminate or reduce the damage of bacteria to human skins.

\subsubsection{Function of Skin Care and Beatifying}

The water content of healthy skin stratum corneum is 10 to $20 \%$, and then the skin is smooth, moist and flexible. If the water content of skin stratum corneum is not enough for a long time, phenomena of coarseness, cracking, the wrinkle will appear, accelerating skin aging.

Containing a variety of amino acids beneficial to the human body, silk fibroin of silk fabrics is capable to enhance human skin cell vitality through its own mechanism, playing a role of skin nourishing and anti-aging (Lu, 2013, p. 7; Gu, 1990). Such as threonine and serine can improve skin blood circulation, and leucine can maintain the metabolism of the skin surface lipid and membrane, keeping the skin smooth, moist and elastic (Ou, 2015 , p. 12; Ou, 2002, pp. 42-44). Serine can nourish skin, helping to treat symptoms such as cracking and chapping of the skin (Ou, 2002, pp. 42-44). Glycine can protect against ultraviolet sunburn and methionine, valine and isoleucine etc. can withstand the sunshine radiation, reducing skin pigmentation and so on.

Furthermore, clinical trials demonstrated that silk knitwear is well adapted to regulate body temperature to the effect of relaxation during wearing (Mao, 1999, p. 54), and to prevent vascular sclerosis, hypertension, cerebral thrombosis, and senile stroke to some extent (Li, 2014, pp. 47-50). These functions will not be explored in the study due to rare mention by consumers in the follow-up interviews.

Due to the inherent correlation between various indicators, it is found that some consumers can not accurately distinguish between the various functions during the small sample survey. Therefore, "anti-ultraviolet radiation", "adsorption of harmful gases", "treatment of pruritus", "skin care" were combined as "silk fabrics have a certain effect of skin protection and beatifying". "Anti-bacteria" and "anti-mite, mildew proof, anti-allergy" were combined as "silk fabrics have a certain function of anti-mite, anti-microbial, anti-allergy". Meanwhile, "silk fabrics are natural, healthy and environmentally friendly" was added considering proposals from respondents. At last, cognitive quantitation table of healthcare function of silk fabrics came into being as shown in Table 1 .

Table 1. Cognitive Quantitation Table of Healthcare Function of Silk Fabrics

\begin{tabular}{|c|c|c|c|c|c|c|}
\hline SN & Questions & $\begin{array}{c}\text { No } \\
\text { Understanding }\end{array}$ & $\begin{array}{c}\text { Little } \\
\text { Understanding }\end{array}$ & Uncertain & $\begin{array}{c}\text { Basic } \\
\text { Understanding }\end{array}$ & $\begin{array}{c}\text { Full } \\
\text { Understanding }\end{array}$ \\
\hline 1 & $\begin{array}{l}\text { Silk fabrics have a certain function of } \\
\text { anti-mite, anti-microbial, anti-allergy. }\end{array}$ & 1 & 2 & 3 & 4 & 5 \\
\hline 2 & $\begin{array}{l}\text { Silk fabrics have a certain effect on } \\
\text { skin protection and beautifying. }\end{array}$ & 1 & 2 & 3 & 4 & 5 \\
\hline 3 & $\begin{array}{l}\text { Silk fabrics are natural, healthy and } \\
\text { environmentally friendly. }\end{array}$ & 1 & 2 & 3 & 4 & 5 \\
\hline
\end{tabular}

\subsection{Research Methods and Principles}

The questionnaire consists of two parts. In the first part of which is perception status of the healthcare function of silk fabrics from respondents consisted of three structural questions detailed as three "items" of which are all single selections in the cognitive scale (Table 1). In the second part of which is the demographic characteristics of the respondents in the form of single selection structural questions for the comparison of cognitive differences, including nine aspects as gender, age, the highest education, income, occupation type, personal preferences, years of residence in Hangzhou, silk fabrics purchase experience, whether silk industry practitioners.

In order to make a statistical analysis of survey results, scores degreed as 1, 2, 3, 4, 5 to "no understanding", "little understand", "uncertain", "basic understanding", "full understanding" respectively according to perceived degree on each indicator of respondents' perception of healthcare function of silk fabrics of garment to obtain the perceptual score $S_{i j}$ of the respondents $i$ on the natural attributes $j$ of the silk fabrics and then calculate the individual perceptual degree $\mathrm{Si}$ and the single item average perceptual degree $\mathrm{MS}_{\mathrm{j}}$ and average perceptual degree of all the samples. The formula is as follows:

$$
\mathrm{S}_{\mathrm{i}}=\sum_{j=1}^{5} \mathrm{Sij}
$$




$$
\begin{gathered}
\mathrm{MS}_{\mathrm{j}}=\frac{1}{n} \sum_{i=1}^{n} S i j \\
\mathrm{MS}=\frac{1}{n} \sum_{j=1}^{5} \quad \sum_{i=1}^{n} S i j
\end{gathered}
$$

The questionnaire data were recorded and analyzed with statistical software SPSS19.0 and charts were drawn with excel13.0.

\section{Survey Results and Analysis}

\subsection{Sample Composition}

A total of 400 questionnaires were distributed at shopping malls, colleges and subway stations in Hangzhou, and 333 valid questionnaires were collected, of which the effective recovery rate was $83.25 \%$. The surveyed population with the demographic characteristics shown in table 2 covered by the questionnaire can basically represent the average cognitive status of the public.

\begin{tabular}{|c|c|c|c|c|}
\hline Item & & Group & Sample & Effective Percentage (\%) \\
\hline \multirow{2}{*}{ Gender } & 1 & Male & 109 & 32.7 \\
\hline & 2 & Female & 224 & 67.3 \\
\hline \multirow{5}{*}{ Age } & 1 & Below 25 & 70 & 21.0 \\
\hline & 2 & Between 26 35 & 118 & 35.4 \\
\hline & 3 & Between 36 45 & 81 & 24.3 \\
\hline & 4 & Between $46 \sim 55$ & 42 & 12.6 \\
\hline & 5 & Above 55 & 22 & 6.6 \\
\hline \multirow{3}{*}{ The highest education } & 1 & College and below & 94 & 28.2 \\
\hline & 2 & Bachelor & 143 & 42.9 \\
\hline & 3 & Postgraduate and above & 96 & 28.9 \\
\hline \multirow{3}{*}{ Occupation type } & 1 & Working in enterprises or institutions & 215 & 64.6 \\
\hline & 2 & Freelancer or other & 33 & 9.9 \\
\hline & 3 & Student & 85 & 25.5 \\
\hline \multirow{4}{*}{ Monthly Income } & 1 & Less than $3500 \mathrm{RMB}$ & 101 & 30.3 \\
\hline & 2 & Between 3501 6000 RMB & 89 & 26.7 \\
\hline & 3 & Between 6001 10000 RMB & 85 & 25.5 \\
\hline & 4 & Above $10000 \mathrm{RMB}$ & 58 & 17.4 \\
\hline \multirow{2}{*}{$\begin{array}{c}\text { Whether silk industry } \\
\text { practitioners }\end{array}$} & 1 & Consumer & 239 & 71.8 \\
\hline & 2 & Silk industry practitioner & 94 & 28.2 \\
\hline \multirow{2}{*}{ personal preferences } & 1 & Like & 210 & 63.1 \\
\hline & 2 & Not like & 123 & 36.9 \\
\hline \multirow{4}{*}{$\begin{array}{c}\text { years of residence in } \\
\text { Hangzhou }\end{array}$} & 1 & Less than one year & 209 & 62.8 \\
\hline & 2 & $1 \sim 3$ years & 18 & 5.4 \\
\hline & 3 & $4 \sim 10$ years & 35 & 10.5 \\
\hline & 4 & More than 10 years & 71 & 21.3 \\
\hline \multirow{2}{*}{$\begin{array}{l}\text { silk fabrics purchase } \\
\text { experience }\end{array}$} & 1 & Yes & 262 & 78.7 \\
\hline & 2 & No & 71 & 21.3 \\
\hline
\end{tabular}

Table 2. The Demographic Characteristics of the Surveyed Population

\subsection{Reliability Analysis}

In this study, Cronbach's internal coherence coefficient ( $\alpha$ coefficient) was used to analyze the reliability of the quantization index. When Cronbach's $\alpha$ was less than 0.7, it belongs to low reliability and should be rejected to use. Reliability analysis results show that the $\alpha$ coefficient is 0.870 (Table 2) of the study data through a small 
sample survey, higher than 0.7 obviously, indicating that the questionnaire as a whole with a high degree of reliability to be used.

Table 3. Scale Reliability Analysis

\begin{tabular}{ccc}
\hline Item & No of Items & Cronbach's Alpha \\
\hline Healthcare function cognition & 3 & 0.870 \\
\hline
\end{tabular}

\subsection{Cognitive Differences}

The average score of public cognition on the healthcare function of silk fabrics of garment is 3.92, ranging from high to low natural, healthy and environmentally friendly function (4.25), skin protection and beautifying (3.76), function of anti-mite, anti-bacteria and anti-allergy (3.75) respectively, shown as black fold line in Figure 1.

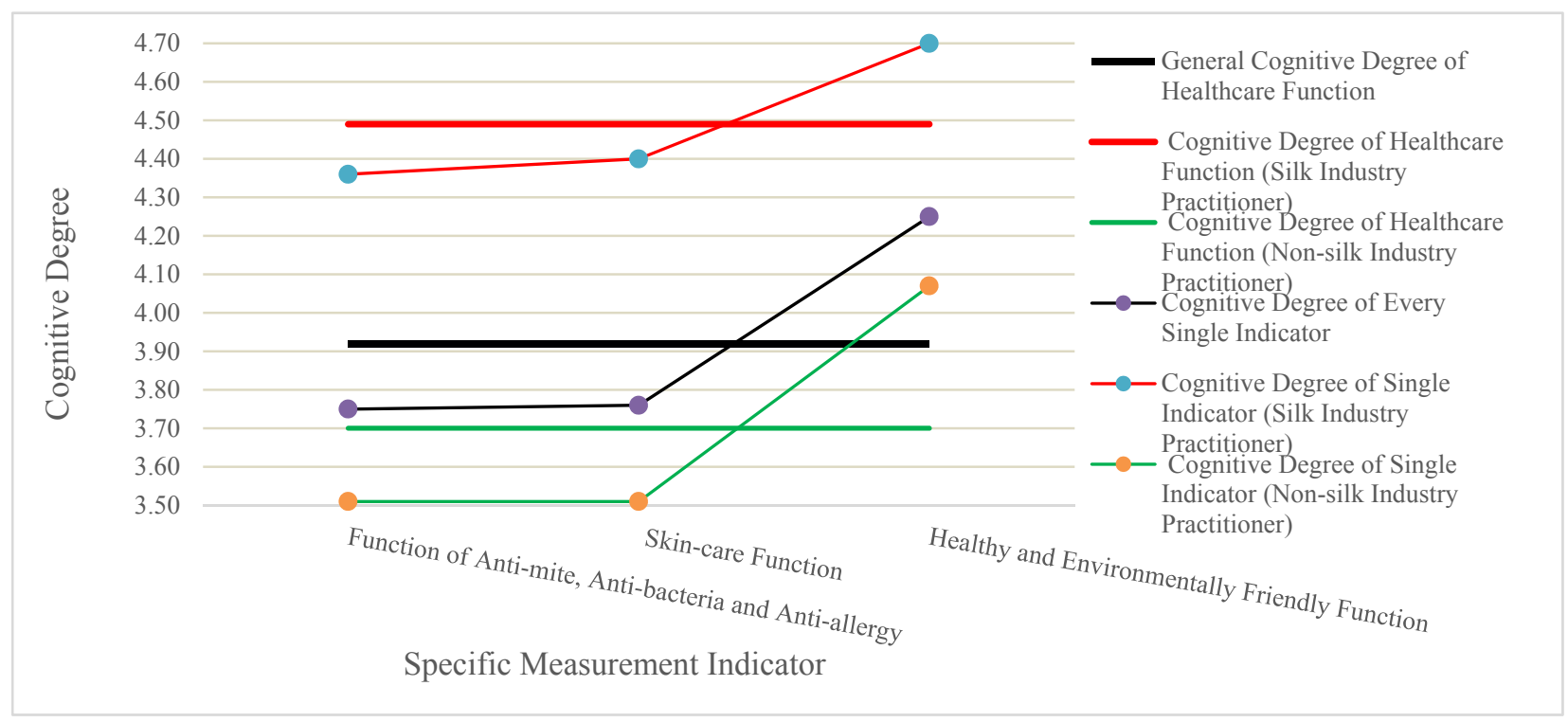

Figure 1. Cognitive Degree of Healthcare Function of Silk Fabrics of Garment

Regarding the calculation of average cognitive degree MS of healthcare function of silk fabrics of the garment, it was calculated by groups with items of gender, age, income, occupation, industry, purchase and use experience, and whether the silk industry practitioners or not etc. respectively (see Figure 2).

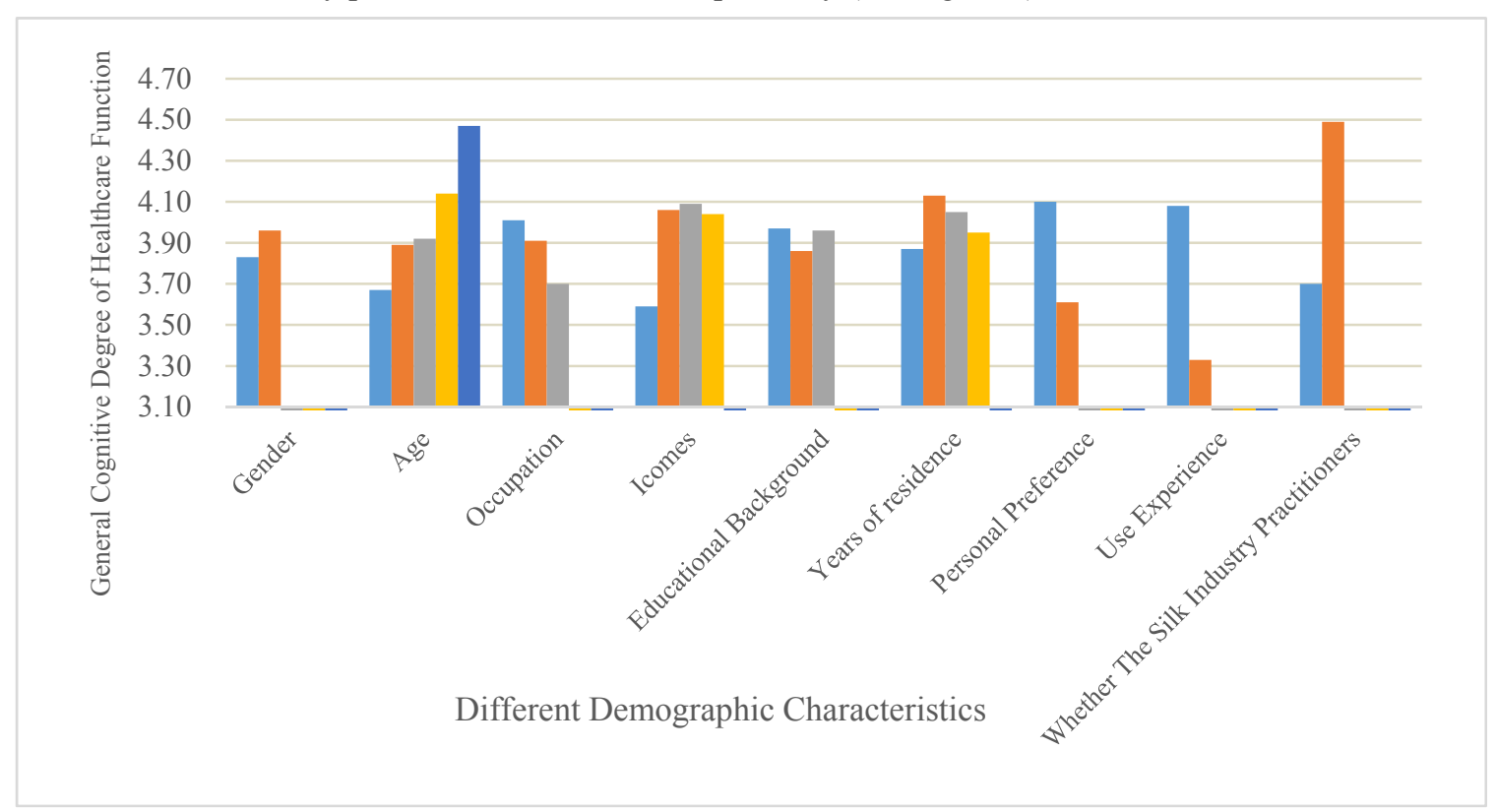

Figure 2. Average Cognitive Degree of Different Demographic Groups 
Using individual cognitive level $\mathrm{Si}$ of different groups as data sample, $\mathrm{T}$ test of independent samples will be taken for those groups with only two comparative data (gender, personal preferences, use experience, whether the silk industry practitioners), and $\mathrm{F}$ test ( $\mathrm{P}>0.05$, there is no significant difference) will be taken firstly those groups with three and more comparative data (age, career, income, educational background and years of residence in Hangzhou) and then further $\mathrm{T}$ test of independent samples on the maximum and minimum population within the group. The results are shown in Table 3.

Table 4. Diversity of The Average Cognitive Difference Between Groups with Different Demographic Characteristics

\begin{tabular}{|c|c|c|c|c|c|c|c|c|}
\hline \multirow{3}{*}{ Item } & \multicolumn{7}{|c|}{$\mathrm{t}$-test for Equality of Means } & \multirow[t]{3}{*}{$\begin{array}{c}\text { Remarks } \\
\text { (Comparative Group) }\end{array}$} \\
\hline & \multirow[t]{2}{*}{$\mathrm{t}$} & \multirow[t]{2}{*}{$\mathrm{df}$} & \multirow{2}{*}{$\begin{array}{l}\text { Sig. } \\
\text { (2-tailed) }\end{array}$} & \multirow{2}{*}{$\begin{array}{c}\text { Mean } \\
\text { Difference }\end{array}$} & \multirow{2}{*}{$\begin{array}{l}\text { Std. Error } \\
\text { Difference }\end{array}$} & \multicolumn{2}{|c|}{$\begin{array}{c}95 \% \text { Confidence Interval } \\
\text { of the Difference }\end{array}$} & \\
\hline & & & & & & Lower & Upper & \\
\hline Gender & -1.160 & 331 & .247 & -.131 & .113 & -.353 & .091 & - \\
\hline $\begin{array}{l}\text { Personal } \\
\text { Preference }\end{array}$ & 4.612 & 331 & .000 & .492 & .107 & .282 & .702 & - \\
\hline $\begin{array}{l}\text { Use } \\
\text { Experience }\end{array}$ & 6.116 & 331 & .000 & .752 & .123 & .510 & .993 & - \\
\hline \multirow{2}{*}{$\begin{array}{l}\text { Whether The } \\
\text { Silk Industry } \\
\text { Practitioners }\end{array}$} & -7.239 & 331 & .000 & -.793 & .110 & -1.009 & -.578 & - \\
\hline & -2.408 & 110 & .018 & -.476 & .198 & -.868 & -.084 & Group 1\& Group 4 \\
\hline \multirow[t]{2}{*}{ Age } & -3.551 & 90 & .001 & -.803 & .226 & -1.252 & -.354 & Group 1\& Group 5 \\
\hline & -2.786 & 138 & .006 & -.580 & .208 & -.991 & -.168 & Group 2\& Group 5 \\
\hline \multirow[t]{2}{*}{ Occupation } & 2.571 & 298 & .011 & .311 & .121 & .073 & .550 & Group $1 \&$ Group 3 \\
\hline & -3.194 & 188 & .002 & -.465 & .146 & -.753 & -.178 & Group $1 \&$ Group 2 \\
\hline \multirow[t]{2}{*}{ Income } & -3.539 & 184 & .001 & -.496 & .140 & -.772 & -.219 & Group 1\& Group 3 \\
\hline & -2.669 & 157 & .008 & -.449 & .168 & -.782 & -.117 & Group 1\& Group 4 \\
\hline $\begin{array}{l}\text { Educational } \\
\text { Background }\end{array}$ & .911 & 235 & .363 & .114 & .125 & -.132 & .360 & Group 1\& Group 2 \\
\hline $\begin{array}{l}\text { Years of } \\
\text { residence in } \\
\text { Hangzhou }\end{array}$ & -1.127 & 225 & .261 & -.259 & .230 & -.711 & .194 & Group $1 \&$ Group 2 \\
\hline
\end{tabular}

Note: only the data under the condition of "hypothetical mean difference equals"; sig for the P value.

\subsubsection{Gender}

Based on the $\mathrm{P}$ value, it can be concluded that gender differences have no significant effect on the cognition of health function $(\mathrm{P}>0.05)$ at the $5 \%$ confidence interval (see Table 3 ).

\subsubsection{Personal Preference}

Personal preference has a significant effect on the cognitive function of health care $(\mathrm{P}<0.05)$, and the cognition degree of people who love silk garments (4.10) is significantly higher than that of the people who do not like silk garments (3.61) (see Table 3).

\subsubsection{Purchase and Use Experience}

The purchase and use experience of silk garment has a significant effect on the cognition of health function ( $\mathrm{P}$ $<0.05$ ), and the cognition degree of people who had the experience of buying and using silk garment (4.08) was significantly higher than that of those who did not (3.33) (see Table 3).

\subsubsection{Whether the Silk Industry Practitioners or Not}

The author analyzed the cognitive difference on each indicator based on the comparative survey targets of the 
silk industry practitioners and non-silk industry practitioners. It was shown that whether the silk industry practitioners or not has a significant effect on the cognition of healthcare function of silk fabrics $(\mathrm{P}<0.05)$ in Table 3. The average cognition degree of the silk industry practitioners (4.70) is significantly higher than the non-silk industry practitioners (4.07), moreover, higher on every indicator (see Figure 1). On one hand, questions in the quantization scale questionnaire have been recognized by the silk industry and given a high score; on the other hand, the cognition state of the silk industry practitioners has pulled up the average value even though the general consumer's cognition degree is relatively low (4.07).

\subsubsection{Age}

The general cognition degree of the healthcare function of silk fabrics is shown in Figure 2 that 3.67 for people aged 25 and below, 3.89 for people aged between 26 and 36, 3.92 for people aged between 36 and 45, 4.14 for people aged between 45 and 55, and 4.47 for people aged 55 and above. The result shows a clear positive correlation that the higher the age of the respondents the higher cognition degree of the healthcare function of silk fabrics.

\subsubsection{Occupation}

There is a certain difference in the groups of different occupations regarding the cognition state of the healthcare function of silk fabrics. The cognition degree of people work in enterprises and institutions (4.01) is significantly higher than that of students (3.70).

\subsubsection{Income}

There is a certain cognition difference within the group on the healthcare function of silk fabrics when coming to people with different income. The cognition degree of people with monthly income of 3,500 yuan or less is significantly lower than that of other groups (see Table 3). Meanwhile, there is a certain positive correlation between the level of income and cognition degree. The higher the monthly income of respondents, the higher cognition degree shows on the healthcare function of silk fabrics. The highest point appeared groups with monthly income between 6001RMB and $10000 \mathrm{RMB}$, and then slightly fell (see Figure 2).

\subsubsection{Educational Background}

The survey results show that there is no significant difference $(\mathrm{P}>0.05)$ in cognition degree on healthcare function of people with different educational backgrounds (see Table 3).

\subsubsection{Years of residence in Hangzhou}

Hangzhou with a long history of producing and consuming silk garments has always enjoyed the reputation of "the capital of silk and the capital of women's dress". Therefore, the group comparison was set based on the consumption that the cognition degree of Hangzhou people is significantly higher than that of non-Hangzhou people, and then four groups were set up for the respondents based on their years of residence in Hangzhou as shown in Table 2. However, the survey results showed that the years of residence in Hangzhou has no significant effect on the cognition of the healthcare function of silk fabrics $(\mathrm{P}>0.05)$ as shown in Table 3. Furthermore, the highest cognition degree appeared in those who lived in Hangzhou between 1 and 3 years, higher than those living in Hangzhou between 4 and 10 years (4.05) and those over 10 years (3.95).

\section{Conclusions and Recommendations}

This paper has developed a quantization table of three indicators for the cognition of healthcare function of silk fabrics of garment including anti-mite, anti-bacteria and anti-allergy, healthy and environmentally friendly function, and skincare in means of streamlining related literature on healthcare functions of garment and consumer interviews. Through the questionnaire survey, the statistical analysis of the 333 collected data shows that: (1) among three indicators reflecting the healthcare functions of silk fabrics, "natural, healthy and environmentally friendly" (4.25) is relatively high in public cognition, while "anti-mite, anti-bacteria and anti-allergy" (3.75) and "skin-care function" (3.76) are less recognized. (2) Factors including personal preferences, purchase and use experience, and whether the silk industry practitioners have a significant impact on the cognition degree of the healthcare function of silk fabrics of garments, while gender, educational backgrounds, years of residence in Hangzhou and other factors have no significant effect. (3) Low cognitive degree of healthcare function of silk fabrics (less than the average of 3.92) appeared in people with characteristics as men, aged younger than 35 years old, not working in enterprises or institutions, monthly income less than 3,500 RMB, bachelor degree, years of residence less than 1 year in Hangzhou, non-silk lover, no silk clothing purchase experience, non-silk industry practitioners.

There are three aspects in need of further research in this paper. First, in the downward aspect, cognitive scale 
items in the quantization table for the cognition of healthcare function of silk fabrics of the garment should be refined. Considering public's limited general cognition of silk fabrics of garment, this study combined some easily confused scale items after the small sample survey, for instance, "silk fabrics has certain anti-mite, antibacterial and anti-allergic functions" containing three functions, resulting in difficulty in answering due to high degree of summarization, of which the public partially recognized while partially rejected. Indicators can be developed and refined in the healthcare functions of comfort, hygiene, and protection respectively for the quantization table. Meantime, the author should trace back to the source for authentication to support each quantization indicator that lacks literature support through specific scientific experiments and research data. Second, from the demographic point of view, there is a certain effect on the significance of the cognitive difference of comparison within groups due to uneven distribution of samples. For instance, there were 6 alternative answers for "years of residence in Hangzhou" at the beginning of the survey including no living experience in Hangzhou (tourists, by-passers), 1 year or less, 1 to 3 years, 4 to 10 years, 11 to 20 years, more than 20 years. However, numeric results of no living experience in Hangzhou (tourists, by-passers), 11 to 20 years, and more than 20 years were only single digits. Therefore, corresponding samples were deleted or merged. Samples of no living experience in Hangzhou can be increased for further research to conclude cognitive difference between Hangzhou people and non-Hangzhou people. Third, the reasons behind the cognitive differences and the application of research findings need further study.

\section{Acknowledgments}

The authors would like to thank Donghua University, Hangzhou Vocational \& Technical College and Shanghai University of Engineering Science. Also, many thanks for the supporting of the project of school-enterprise cooperation of visiting engineer from College and University of Education Department of Zhejiang Province (Project name is the research and development of knitwear fabric). Meanwhile, thanks to the editor and the readers of Asian Social Science.

\section{References}

Gu, J. S. (1990). Nutritional Effects of Silk Proteins on Humans. Journal of Silk, 9, 24.

He, Z. Q. (1998). A Diverse Range of Silk Products. Journal of Foreign Silk, (1), 26-28.

Leng, S. Y. (1988). A Review of Garment Function Research. Journal of Silk, (7), 34-36.

Li, H. Y., Zhang, W. Y., \& Li, J. (2007). Literature Review of Functional Clothing. Journal of Silk, (4), 45-47. https://doi.org/10.3969/j.issn.1001-7003.2007.04.017.

Li, Q. Z., \& Wang, G. S. (2014). Design Thinking of Health Protection T-shirt for the Aged. Journal of Silk, 51(2), 47-50. https://doi.org/10.3969/j.issn.1001-7003.2014.02.010

Lu, Q. W. (2013). Shape Formation of Silk Pleated Garments. Shanghai: Donghua University.

Mao, L. L. (1999). Green silk knitwear health functions. Journal of Silk, (3), 54.

Ou, P. Y. (2015). Research and Development of Temperature-controlled Warm-type Silk Fabrics. Suzhou: Suzhou University.

Ou, Y. J. (2002). The Healthcare Function of Silk Garment. Journal of Jiangsu Silk, (6), 42-44.

Wan, Q., \& Hu Q. (2012). Comprehensive Overview of the Development and Application of Silk Proteins. Modern Silk Science \& Technology, 27(3), 111-113.

Wang, X. Q., Ji, X. L., \& Xie, W. Y. (1989). A Study of Fungi-proofing of Fabrics of Garment. Journal of Textile, 10(6), 31-32.

Xu, C. D., \& Liang, X. Q. (1995). A Preliminary Discussion on The Healthcare Function of Mulberry Silk and Silk fabrics. Journal of Silk, (12), 54-57.

Yang, M. Y. (2011). Research on the Comfortable and Healthy Function of Silk Clothing. Hangzhou: Zhejiang University.

\section{Copyrights}

Copyright for this article is retained by the author(s), with first publication rights granted to the journal.

This is an open-access article distributed under the terms and conditions of the Creative Commons Attribution license (http://creativecommons.org/licenses/by/4.0/). 